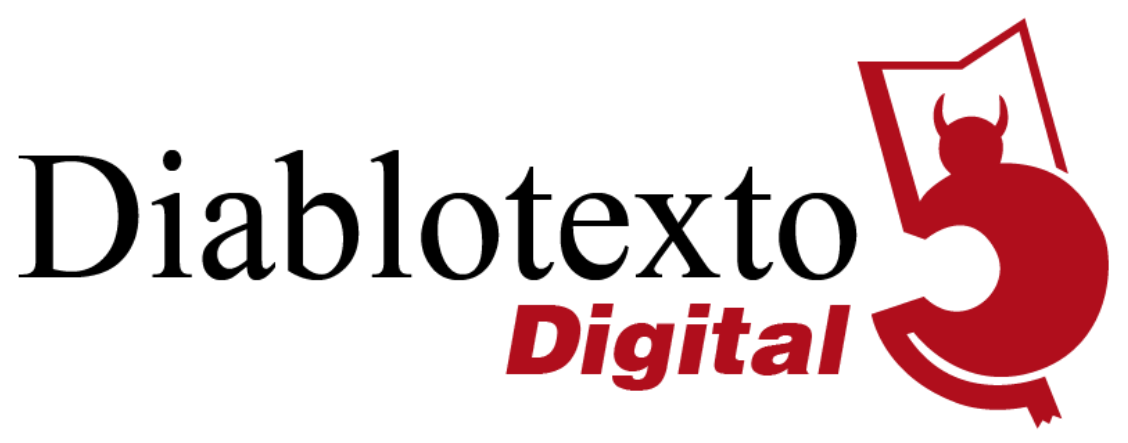

\title{
La sátira cervantina de la épica a la luz de las primeras décadas de su historia vernácula
}

\author{
Cervantes' Satire of the Epic in the Light of the \\ First Decades of its Vernacular History
}

\section{Aude Plagnard (UniVersite PaUl-ValeRY'1)}

\begin{abstract}
Resumen: El escrutinio de la biblioteca de don Quijote consagró una distinción nítida entre la épica caballeresca, censurada junto con las novelas de caballería que provocaron la locura del famoso hidalgo, y la épica de tema histórico que reivindicaba atenerse a la verdad y autenticidad característica de las crónicas, más tardía y más acorde con la experiencia de soldado de Cervantes. Esta dicotomía sin duda le fue sugerida a Cervantes por los propios poemas históricos -con La Araucana de Alonso de Ercilla a la cabeza de ellos- que desarrollaron su proyecto poético en contra de las fabulosas ficciones caballerescas. Este artículo propone reconsiderar esta dicotomía, característica de la épica de la década de 1580, a la luz de la historia del género desde su desarrollo en castellano, a partir de la década fundadora de 1550.
\end{abstract}

Palabras clave: épica culta, novelas de caballería, traducciones, Don Quijote

\begin{abstract}
The scrutiny of Don Quixote's library enshrined a clear distinction between the chivalric epic, censored along with the novels of chivalry that provoked the madness of the famous hidalgo, and the later historical epic that claimed to adhere to the truth and authenticity characteristic of the chronicles, more in accord with Cervantes' experience as a soldier. This dichotomy was undoubtedly suggested to Cervantes by the historical poems themselves-with Alonso de Ercilla's La Araucana at their head-which developed their poetic project against the fabulous chivalric fictions. This article proposes to reconsider this dichotomy, characteristic of the epic of the 1580s, in the light of the history of the genre since its development in Castilian, from the founding decade of the 1550 s onwards.
\end{abstract}

Key words: erudite epic, chivalric Novels, Translations, Don Quijote

${ }^{1}$ Univ Paul Valéry Montpellier 3, IRIEC EA 740, F34000, Montpellier, France. 
¿Qué concepción y qué práctica del género épico acompañaron el nacimiento de la novela moderna en España? Para responder a esta pregunta, tomaremos como punto de partida el más conocido de los juicios sobre el género, inserto justamente en una novela: el escrutinio de la biblioteca de don Quijote.

\section{La épica culta en la biblioteca de don Quijote}

La irónica mención de La Galatea, en el sexto capítulo del Quijote, constituye sin duda el punto álgido del escrutinio de la biblioteca del hidalgo y podría marcar la conclusión de lo que es quizás la más famosa pieza de crítica literaria del Siglo de Oro. Sin embargo, a manera de colofón, antes de que se canse el Cura y despierte don Quijote, vuelven a surgir, en la biblioteca y en el sexto capítulo, cuatro obras que no encajan exactamente en ninguna de las dos categorías anteriormente sometidas a examen: no son "cuerpos de libros grandes, muy bien encuadernados", dedicados a las caballerescas aventuras en prosa; y si bien, por el tamaño, entran en la categoría de los "libros pequeños" examinados a continuación, se distinguen, por el tema, de la ficción pastoril y de la lírica cancioneril que predominan en la segunda parte de la biblioteca del hidalgo. El puñado de obras salvadas in extremis del fuego son La Araucana de Alonso de Ercilla (1569, 1578, 1589), La Austríada de Juan Rufo (1584), El Monserrate de Cristóbal de Virués (1587) y Las lágrimas de Angélica de Luis Barahona de Soto (1586); cuatro obras, a todas luces, muy distintas en sí, pero todas representativas del apogeo de la llamada épica culta quinientista por el decenio de $1580^{2}$.

Si los dos primeros títulos mencionados ilustran el ámbito de la épica militar -americana y mediterránea respectivamente-, mientras que la tercera pertenece a la tradición sacra, la presencia de las tres, juntas en la biblioteca y

\footnotetext{
2 Hasta la fecha, tan solo existen tres obras críticas recapitulativas del desarrollo del género épico en lengua castellana: al clásico monográfico de Franck Pierce, La poesía épica del siglo de oro (1961), se sumaron dos monografías más específicas, que observan el género vernáculo desde el punto de vista de la recepción de dos modelos cruciales de la revolución que marcó el Renacimiento: L'Arioste en Espagne de Maxime Chevalier (1966) e Imitación virgiliana y propaganda política en la épica española del siglo XVI de Lara Vilà (2001).
} 
evocadas en la misma réplica del barbero, se explica sin duda por el destacado lugar que ofrecen a la representación de la batalla de Lepanto, en la que participó Cervantes con las consecuencias que él mismo puso de relieve en el prólogo de las Novelas ejemplares (Leavitt, 1968; Pierce, 1961: 464). Ahora bien, las tres obras comparten el aprecio suscitado en el Cura, que ve en ellas "las más ricas prendas de poesía que tiene España" (Cervantes, 2015 [1605]: 94). En conexión con estas obras de inspiración histórica, que cultivaron la narración verdadera y están en la base de la reflexión sobre la identidad hispana desarrollada por Elizabeth Davis (2000), se hallan otros tres poemas mencionados al principio del capítulo siguiente y que el repentino despertar de don Quijote condena al fuego sin examen previo: la Carolea de Jerónimo Sempere (1560), el León de España de Pedro de la Vecilla Castellanos (1586) y una crónica de Luis de Ávila sobre los hechos de armas del Emperador Carlos $\mathrm{V}^{3}$. Estos seis títulos forman un conjunto coherente no solo por su común pertenencia al género de la narración de guerra y, en los cinco primeros casos, de la épica culta, sino también, como mostró Lara Vilà, por atenerse a "una descripción de la guerra realista y verdadera, escrita en muchos casos por autores que, como el propio Cervantes, son también soldados" (2011: 139).

Colocada entre estos dos tríos de poemas, la última obra mencionada en el sexto capítulo del Quijote se distingue de las anteriores por seguir la vena más caballeresca de la materia ariostesca. Los comentarios del Cura sobre Las lágrimas de Angélica llaman la atención en cuanto a su adscripción genérica: su autor, "uno de los más felices poetas del mundo", que fue en esta obra continuador del Orlando furioso, es alabado también en cuanto traductor de varios episodios de las Metamorfosis de Ovidio (Cervantes, 2015 [1605]: 94). La asociación entre el poema latino y el italiano no tiene por qué sorprendernos: ya habían sido comparados y asociados, en los debates italianos sobre la épica, por "la multiplicidad y la variedad de sus narraciones"

\footnotetext{
${ }^{3}$ Sobre la identificación de esta última obra, concuerdo con el análisis de Lara Vilà, que la atribuye al cronista (Ávila, 1549) e invalida la hipótesis de una confusión con el Carlo famoso de Luis de Zapata.
} 
(Javitch, 1991: 73). En esta labor de parangonar el poema italiano con el clásico de Ovidio, el formato editorial diseñado por el impresor veneciano Giolito de Ferrari y el editor Ludovico Dolce, desde la década de 1550, había desempeñado un papel importante: el tamaño in cuarto y la disposición del texto en dos columnas -la que más se asemejaba a los "libros grandes" de las novelas de caballería- (Javitch, 1991: 74-75). El poema de Barahona de Soto se valía de la materia del Orlando para desarrollar la ficción sentimental desde una perspectiva genérica distinta a la de las obras en formato pequeño anteriormente examinadas y salvadas de la hoguera por el Cura, aunque sin recurrir al formato editorial caballeresco anteriormente descrito para el Orlando y las Metamorfosis italianas.

Ahora bien, el destino de Las lágrimas de Angélica contrasta, como bien ha mostrado Lara Vilà, con el de los otros poemas épicos inspirados en la materia ariostesca que aparecen mezclados entre los libros de caballería de la sección primera de la biblioteca de don Quijote. En efecto, entre el Amadís y Tirante el Blanco, que pertenecen stricto sensu al género novelesco, se encuentran algunas ficciones épicas que mimetizaban, en su formato editorial y en la materia convocada, la épica caballeresca italiana: el Roncesvalles de Francisco Garrido de Villena (1555) y Bernardo del Carpio de Agustín Alonso (1585). Estas obras aparecen mencionadas a continuación del Espejo de caballerías, una compilación en prosa sobre la materia medieval de Francia inspirada en Boiardo y Ariosto. Para estos poetas italianos, cuando leídos en lengua original, el Cura muestra el máximo respeto, tanto por la "invención" como por el carácter "cristiano" de la fábula, y manda que sean depositados en el fondo de un pozo seco en vez de quemados (Cervantes, 2015 [1605]: 87). Muy al contrario, las traducciones castellanas de las mismas -probable referencia a la del "capitán" Jerónimo de Urrea (Cervantes, 2015 [1605]: 88)son censuradas con máximo rigor, al igual que las continuaciones anteriormente citadas de Villena y de Alonso.

De este breve examen de la presencia de obras épicas en la biblioteca de don Quijote, deducimos que Cervantes concebía lo que hoy denominamos 
la épica culta como un género dispar, cuyas distintas ramas juzgaba de una manera antitética. La dicotomía apuntada por Lara Vilà impera claramente en esta jerarquía. Por un lado, se condena la épica caballeresca de origen italiano por el carácter engañoso de sus ficciones, que participaron en la locura de don Quijote, y por su mala calidad poética al trasponer en castellano la ottava reale italiana. Sobre este particular, la biblioteca, que mezcla obras de caballería en prosa y en verso, apoya la hipótesis del canónigo del capítulo XLVII, según la cual la épica convoca a la par las "ciencias de la poesía y de la oratoria" y "bien puede escribirse en prosa como en verso" (Cervantes, 2015 [1605]: 602). Al contrario, la épica histórica y militar no solo se salva de la hoguera, sino que se coloca en la cumbre de los géneros, como el modelo a seguir entre las letras castellanas. Entre estas dos opciones, se distingue, sin embargo, una tercera vía: la de la épica amorosa de factura poética más cuidada, con Las Lágrimas de Angélica, que Cervantes admiraba sin duda por la calidad de sus versos y por la amistad que unía a los dos hombres.

Más allá de estas distinciones, llama la atención que la biblioteca de don Quijote se centra principalmente en una época clave para el desarrollo del género: la década de 1580. En efecto, todas las obras que acabo de citar vieron la luz por primera vez por aquellos años ${ }^{4}$ o bien volvieron a pasar por la imprenta en aquel entonces ${ }^{5}$. Tan solo dos textos se adelantan a este perfil: la Carolea de Sempere (1560) y el Comentario de la guerra de Alemaña de Luis de Ávila que contó con varias ediciones en castellano e italiano entre 1548 y 1552. Semejante interés por la década de 1580 no puede sorprendernos, pues se trata de una década fundadora para la carrera literaria del autor: la de la vuelta de Cervantes a España y a Madrid después del cautiverio argelino, la de la redacción y publicación de la Galatea y, sobre todo, la de la composición de

\footnotetext{
${ }^{4}$ Las de Ercilla (1589-1590 para la primera edición completa en tres partes), de Rufo (1584), de Virués (1587), de Barahona de Soto (1586), de Pedro de la Vecilla Castellanos (1586) y de Alonso (1585).

${ }^{5}$ El Roncesvalles de Garrido de Villena y la traducción del Orlando furioso de Urrea se reeditaron en 1583 en Toledo (por Juan Rodríguez y Pero López de Haro respectivamente). En la misma ciudad y con el mismo impresor se había reeditado dos años antes la traducción del Orlando enamorado del mismo Villena.
} 
la Numancia, una tragedia de tema militar y antiguo en la que se manifiesta claramente la impronta de la épica y en especial de La Araucana (Rupp, 2014: 31-62; King, 1979). Ahora bien, que Cervantes pensara en 1605 la épica desde la década de los 80 del siglo anterior tiene unas consecuencias muy claras y justifica que, al contrario de las opiniones que presta a su personaje, coloque la línea divisoria del corpus épico no entre el verso y la prosa sino en la encrucijada de dos tradiciones literarias que ya presentaban en lengua castellana cierta madurez: la épica caballeresca vs la épica histórica. En el prólogo de La Araucana encontró probablemente Cervantes la formulación más aguda de esta confrontación literaria. Mediante el motivo del prólogo antiariostesco, Alonso de Ercilla se eleva contra el modelo del Orlando furioso:

\author{
No las damas, amor, no gentilezas \\ de caballeros canto enamorados, \\ ni las muestras, regalos y ternezas \\ de amorosos afectos y cuidados, \\ mas el valor, los hechos, las proezas \\ de aquellos españoles esforzados \\ que a la cerviz de Arauco no domada \\ pusieron duro yugo por la espada. (Ercilla, 2021 [1569]: I, 1)
}

Dejar de lado las damas, los caballeros enamorados y la famosa unión entre "arme" y "amori", "cortesie" y "audaci imprese" (Ariosto, 2002: I, 1), para orientar el relato a las proezas y hazañas militares de la patria es un gesto consciente, por parte de Ercilla, que responde a cierta práctica de la épica ya bien asentada cuando tomó la pluma y se explica por el éxito enorme del que gozó el Furioso en la península ibérica.

El propósito de este artículo es volver a examinar la dicotomía ercillana, asumida por Cervantes, a la luz de las primeras décadas de vida de la épica hispánica, a raíz del meridiano del siglo, que marca el punto de partida de la reflexión colectiva en este número monográfico. Si el mecanismo, así descrito, refleja efectivamente la enorme influencia de la épica italiana en la España de mediados del siglo XVI, y si la épica militar se fundó en gran parte en un gesto de rechazo a las fábulas maravillosas, veremos que esta explicación deja de 
lado otros aspectos fundamentales del desarrollo del género: la precocidad de la épica militar y testimonial y la influencia de la épica antigua 6 .

\section{El ciclo orlandino en castellano}

En los albores de la poesía épica española está, sin lugar a dudas, la recepción de la boga caballeresca italiana, que se extendió en aquel entonces por toda Europa (Chevalier, 1966). Mientras que, en Francia, Ariosto y Boiardo se tradujeron en prosa, propiciando una asociación genérica entre épica y las novelas de caballería que sin duda sería del gusto de don Quijote, España recibió el Orlando enamorado y el Orlando furioso en una posición genérica similar a la que tenían en Italia, es decir, en cuanto poesía narrativa. Entre 1549 y 1555 nació lo que podríamos llamar un ciclo orlandino, a lo largo del cual un puñado de poetas procedieron a la castellanización de lo que habían bautizado como romanzo quienes querían sustraer el Furioso al código aristotélico, en algunos casos en mala parte (Zatti, 1990).

La primera etapa de este ciclo consta de traducciones de los poemas italianos de Boiardo y Ariosto que sirvieron de laboratorio para el aprendizaje de este tipo de narración, tanto en el plano métrico y estilístico, para la imitación de la ottava reale en castellano, como político. En efecto, estas traducciones se inscriben en el marco de la questione della lingua y de la competencia entre naciones modernas: castellanizar el Orlando furioso suponía desviar el poderoso sistema de la dedicatoria ariostesca hacia la alabanza de la familia real habsbúrgica y de la nobleza castellana, y refutar la asociación entre España y el ejército sarraceno, derribando a Orlando del pedestal heroico en el que le colocaba la ficción ariostesca.

\footnotetext{
${ }^{6}$ No abordaremos, en este trabajo, la vivacidad de la vena sacra, perceptible a través de los quince poemas publicados en español sobre temas religiosos -a la cabeza de ellos, sobre la pasión de Cristo- entre 1552 y el Monserrate de Virués (1587), si nos atenemos a los datos recopilados por Franck Pierce en su catálogo (1961). Este último poema ha recibido mayor atención de parte de la crítica (véanse las recientes contribuciones de Lledó-Guillem, 2013 y Oria de Rueda, 2019), aunque los estudios sobre la épica sacra castellana se han desarrollado hasta la fecha a partir del más tardío Isidro de Lope de Vega (Ponce, 2018).
} 
La primera traducción, la de Jerónimo de Urrea publicada a finales de 1549 -que desencadena el agresivo desprecio del Cura de Cervantesemprendió esta tarea quitando los fragmentos del Orlando furioso que despreciaban a los castellanos o hacían el elogio genealógico de la familia de $E_{s t e}{ }^{7}$. De ello resultó una singular versión en 45 cantos, de la que se había eliminado el famoso canto tercero, en el que Bradamante contemplaba su heroica descendencia hasta Hipólido de Este, dedicatario del poema (Ariosto, 2002: 34 y 186-187). Unos años más tarde, el valenciano Francisco Garrido de Villena publicaba una traducción del Orlando enamorado fuertemente marcada por el modelo del Furioso: en ella introducía el sistema ariostesto de los prólogos, actualizando el texto según la moda más reciente, y aprovechando estos lugares clave de la narración para alabar la corte de armas y amores del príncipe Felipe, su propia ciudad, Valencia, y, como no, al dedicatario de su poema, Pedro Luis Galcerán de Borja y Castro-Pinós.

Además de promocionar un nuevo modelo de narración heroica aplicado, aunque de forma marginal todavía, a la celebración del monarca y de los poder locales, estos poemas sirvieron también de valedor lingüístico para la promoción del castellano en poesía. La traducción de Urrea fue la que obtuvo, sin lugar a dudas, el mayor éxito desde este punto de vista. Contribuyó a ello que Jerónimo de Urrea consiguiese lanzar la publicación en Amberes, en las prensas de Martín Nuncio, en el mismo momento en que se encontraba allí su dedicatario, el príncipe Felipe de Habsburgo, que realizaba entonces su felicísimo viaje a través de los territorios europeos de la Monarquía Hispánica. Publicado en el corazón de la corte, el libro rápidamente llamó la atención de los editores europeos más prestigiosos en Europa: Guillaume Rouillé en Lyon (1550 y 1556), Giolito de Ferrari en Venecia (1553) y Marie Borrewater, viuda de Martín Nuncio, de nuevo en Amberes (1558). La reedición de Giolito de Ferrari desempeñó un papel importantísimo, gracias al trabajo editorial de Alonso de Ulloa, que asimiló la imagen del Orlando castellano con la de su

\footnotetext{
7 Véase el prólogo de Cesare Segre en Urrea, así como el balance de octavas suprimidas y añadidas por María de las Nieves Muñiz (Ariosto, 2002, pp. 34 y 53).
} 
original italiano -aplicándole el formato in quarto, los grabados y los argumentos que encabezaban cada canto, característicos de las ediciones italianas del Orlando, y adjuntándole un apéndice erudito de los pasajes más difíciles de comprender del poema. Le dotó además de un léxico castellanoitaliano mediante el cual el poema pasaba a constituir un verdadero manual de introducción al idioma castellano (Kammerer et al., 2015). En algunos casos, el Orlando de Urrea llegó a distribuirse a la par que el de Ariosto: como en Lyon en 1556, cuando Guillaume Rouillé editó por primera vez la versión italiana del poema al mismo tiempo que la versión castellana. Parece indudable que la apuesta de Urrea por la presentación más lúdica y entretenida de la épica caballeresca italiana triunfó dentro y fuera de las fronteras de la monarquía ${ }^{8}$, pese al juicio cervantino que parece censurar los defectos de versificación del poema, por cuanto en este aspecto difícilmente podía llegar a la altura de su original.

Otra traducción contemporánea del Orlando furioso no gozó de semejante éxito. La de Hernando Alcocer se publicó a los pocos meses de la prínceps de Urrea, y todo lleva a pensar que la traducción ad verbum que reivindicaba desde el título, y que buscaba la fidelidad al texto original al precio de algunas torpezas, era una respuesta directa a los rifacimenti de Urrea ${ }^{9}$. Alcocer tomó también el polo opuesto al de su competidor en lo que atañe a la estrategia editorial y comercial, apostando por una traducción literal y sobria, que es al mismo tiempo una toma de partido a favor del poema de Ariosto en los debates italianos sobre epos y romanzo. Así, hizo figurar entre los preliminares de la obra una traducción integral del texto de Fausta da Longiano publicado en 1542 a favor de Ariosto, donde se defendía la naturaleza erudita del texto y su filiación con los clásicos (Plagnard, 2012b: §30).

8 El éxito del poema no disminuyó pasada la década de 1550. Además de las reediciones mencionadas en la bibliografía, el poema volvió a imprimirse de nuevo en 1564 en Barcelona, 1572 en Medina del Campo, 1575 en Venecia, 1578 en Salamanca, 1583 en Bilbao y Toledo.

${ }^{9}$ En el prólogo, reivindica el traductor: "me pareció traducirle en la nuestra castellana, cuanto más fielmente pude, todos sus 46 cantos sin dejar estancia atrás, con la sucesión de la ilustrísima casa de Este, que es el fundamento y sujeto de toda la obra, adonde el autor mostró todo su ingenio, como en el tercero canto lo confiesa, donde dice: «Pienso en estas imágenes poner todo mi ingenio, y todo mi saber» (Alcocer, 1550, f. 2v). 
Si comparamos las dos estrategias de Urrea y Alcocer y su respectiva fortuna, entendemos que el lector de la época adoptó claramente el Orlando furioso como un texto caballeresco y no como un epos erudito, y se dejó convencer por las posibilidades poéticas y encomiásticas que el modelo, una vez debidamente adaptado, proporcionaría desde una lengua vernácula competidora. Los primeros poemas épicos publicados en Castilla prosiguieron con esta opción inicial.

Francisco Garrido de Villena, traductor del Orlando enamorado, se encuentra en la encrucijada entre la primera etapa del ciclo, la de las traducciones, y la segunda, en la que se prosiguió con la materia orlandina con vistas a sacrificar el héroe francés italianizado, Orlando, para hacer emerger frente a él otra figura heroica castellana: la de Bernardo del Carpio (Lara Garrido, 1981: 27-28). El título de la continuación de Villena apuntaba al desenlace: la desaparición del héroe italiano a manos de los españoles en Roncesvalles. Otra continuación contemporánea, la de Nicolás Espinosa (1555, Zaragoza) apostó, al contrario, por subrayar la continuidad con el poema de Ariosto que le sirve de base narrativa: se publicó bajo el título de Segunda parte del Orlando furioso y, en 1557-1558, salió, en la imprenta de Marie Borrewater (viuda de Nuncio), en Amberes, a juego con la traducción de Urrea, titulada para tal ocasión Primera parte de Orlando furioso.

Estas dos continuaciones, redactadas por plumas valencianas, eran competidoras y entregaban su lealtad a dos familias rivales de la ciudad -los Centelles y los Borja- que las ficciones caballerescas elevaron al rango de descendientes de los héroes de la diégesis. El programa político del Roncesvalles iba más lejos todavía al aplicar el programa panegírico del Orlando furioso al heredero del trono hispánico, Felipe de Habsburgo, y su esposa inglesa de la época, María Tudor ${ }^{10}$. Ambos relatos incluyen un héroe vernáculo sacado de las crónicas y del Romancero medievales, Bernardo del Carpio, en cuya victoria sobre Orlando se cifra la moderna rivalidad de España

10 Este aspecto ha sido atentamente analizado por Chevalier (1966: 107-125) y más recientemente por Valsalobre (2003 y 2005) y Plagnard (2012). 
con Francia y la voluntad de restaurar la gloria militar castellana, como lo demuestran muchas de las declaraciones prologales analizadas por Maxime Chevalier. Estas continuaciones, que marcaban el inicio del género épico en España, tuvieron una larga y abundante posteridad.

El ya mencionado Bernardo gozó de una fortuna destacable: fue héroe epónimo del poema de Agustín Alonso (1585) -condenado a la hoguera por el Cura de Cervantes- y origen de la ilustre genealogía de los duques de Osuna en Las lágrimas de Angélica (Lara Garrido, 1981: 29-34). En la continuidad de esta figura, el último tercio del siglo XVI fue fecundo en hibridaciones de este tipo, donde se elevaba al rango de héroe a personajes de la historia medieval castellana. Así, aunque más tardío, el Orlando determinado de Martín Abarca de Bolea y Castro (1578) se presentaba a su vez como una continuación del Orlando enamorado. Más indirectamente, plagiaba en verso la continuación en prosa del ya mencionado Espejo de caballería al mezclar la materia italiana con la leyenda antigua de las Amazonas y con personajes del romancero castellano (Chevalier, 1966: 169-177).

También se celebraron en clave heroica moderna otros personajes del Medioevo castellano: El Cid bajo la pluma de Jiménez de Aillón (1568), Celidón de Iberia por Gonzalo Gómez de Luque (1583) y Florando de Castilla por Jerónimo de Huerta (1588). Para estas obras, Maxime Chevalier propone la etiqueta de "poemas caballerescos"11, bien resumida bajo la pluma de Luque como "de ficción libro[s] en metro" (1583, "dedicatoria", f. s.n.). Tal fue la tercera etapa del ciclo orlandino, bajo el prisma de la cual Cervantes fundó su crítica de las novelas de caballería e, igualmente, el proyecto de reformación del género, para el que contemplaba componer un «famoso Bernardo», que quizás fuera objeto de la descripción de la novela de caballería ideal por el canónigo en el capítulo 47 del Quijote (Eisenberg, 1983).

\footnotetext{
11 "Tous ces poètes, si inégal que soit leur talent, sont animés d'une même intention. Ils veulent unir les suggestions de l'Amadis et les apports du Roland furieux dans une synthèse originale, traiter dans une forme moderne et belle la matière des vieux romans nationaux, créer un poème chevaleresque espagnol" (Chevalier, 1966: 190).
} 


\section{La historia contemporánea como materia épica}

La opción de la épica caballeresca que acabamos de comentar y que consistía en actualizar el legado heroico medieval ornándolo y modernizándolo con las tintas del romanzo italiano, provocó el rechazo de varios autores -en la estela de los cuales parece situarse Cervantes- que prefirieron pensar la heroicidad española desde las especificidades de la guerra moderna y en función de moldes retóricos y genéricos menos estrictamente dependientes de Ariosto. Esta tentativa se plasmó de la forma más llamativa y, quizás, lograda bajo la pluma de dos poetas de renombre: Luis Zapata, en el Carlo famoso (1566), y Alonso de Ercilla, en La Araucana (1569-1589). Examinaremos las fórmulas elegidas por los dos poetas a la luz de sus precedentes, que se remontan, de nuevo, a la década fundacional de 1550.

Cuando Luis Zapata, que había sido paje del príncipe Felipe en la adolescencia y pertenecía a la orden de Santiago, publicó y costeó en 1566 el Carlo famoso, procedió a una innovación importante en el canon épico, cual fue aplicar el modelo de narración ariostesca a la figura histórica del emperador. Que quiso inscribir su poema en la estela del de Ariosto, se distingue nítidamente al examinar la factura del volumen, un in quarto donde las octavas se disponen elegantemente en dos columnas; en la elección de una fábula basada en el entrelacement de intrigas en las que se mezclan varios episodios maravillosos inspirados en el poema italiano; y en cantidad de referencias literales al poema italiano. Esta vez, sin embargo, el modelo se aplicaba a una materia histórica casi contemporánea -los hechos narrados cubren el período de 1522 a 1557, desde el final de la rebelión de las Comunidades hasta la muerte del Emperador- y dotándola de una figura heroica de primer plano en la persona del monarca difunto, Carlos Quinto, cuya biografía y cuyo reinado seguimos a lo largo de unos cincuenta cantos. En este poema culmina, según Miguel Martínez (2011), la expresión de un ethos aristocrático que quiso elevar al emperador al rango de máximo héroe guerrero de su tiempo, tal y como había hecho Tiziano en el famoso Carlos V a caballo en Mühlberg (1548); un ethos que, a su vez, hacía de los nobles cortesanos poetas revestidos de 
estatura heroica (en los casos paralelos de Zapata y Ercilla, ambos hijos de familia noble, de más alcurnia en el caso de Zapata, con padres y madres provistos de cargos palatinos). El problema planteado por la inverosimilitud de los episodios maravillosos trasladados a la historia contemporánea fue fácilmente resuelto por el impresor valenciano Joan Mey (el impresor, unos diez años antes, de los poemas caballerescos de Garrido de Villena), quien los señaló, para los "ciegos, o de ingenio, o de envidia", con un sistema de estrellas al margen de las octavas. Así "los cuentos [...], las ficciones y fábulas" del libro, introducidas para el regocijo del lector, no iban reñidas con la veracidad requerida a una narración sobre la figura contemporánea del monarca, "pues los poetas antiguos y muchos historiadores han usado lo semejante" (f. Aiir).

Si bien el poema de Zapata nunca se reeditó, la fórmula propuesta, en la que se entreveran la historia y hechos reales con digresiones caballerescas, mitológicas o sentimentales, o se revisten los hechos reales de un barniz alegórico-fantástico -figurando por ejemplo las Comunidades como un dragón que el héroe ha de rebatir-, es sumamente original y destaca por la mezcla de modelos antiguos en que se sustenta (Cacho Casal, 2012). Raros son en efecto los poemas que aplicaron episodios de ficción caballeresca a los protagonistas de la historia reciente. En este aspecto sí sobresale la tardía excepción de la Conquista de Granada de Duarte Dias (1590), en la que un episodio muy concreto pone en escena a Fernando el Católico, durante las guerras andaluzas, como vencedor de un gigante en un episodio profético que le permite contemplar las futuras glorias de los reyes de España y Portugal.

Sin embargo, la innovación de Zapata debe leerse a la luz de otra tradición ligeramente anterior, que ya había hecho del emperador y de sus huestes los héroes de ficciones históricas en octava rima, aunque de muy distinta índole. En 1560, Jerónimo Sempere ya había publicado un poema en octavas titulado Carolea, cuya trama y relatos se centraban en la primera mitad del reinado de Carlos Quinto y en las campañas del Milanesado contra 
Francisco I de Francia (primera parte, hasta la batalla de Pavía) y contra el emperador otomano Solimán (segunda parte, hasta terminar el sitio de Viena).

Con todo, el protagonismo del emperador y el tipo de heroísmo al que se veía asociado en esta obra distaba mucho de la vía seguida por Zapata. En primer lugar, la factura de esta obra se distanciaba completamente de la del romanzo y adoptaba un formato más reducido, barato y difundido, el octavo, abandonando la disposición característica del texto en dos columnas. Destaca también, en comparación, la ausencia de episodios maravillosos caballerescos, sustituidos, para el adorno de la acción, por episodios cristianos que polarizan la diégesis, asignando al enemigo francés la visión de una babilonia infernal (primera parte, $\mathrm{VI}$ ), mientras que la contemplación en éxtasis de la Jerusalén celeste se reserva a Carlos Quinto, a quien inspira la campaña y la victoria contra Solimán (segunda parte, XIII), elevándolo a la dignidad de héroe cristiano (Vilà, 2001: 483-494). Pero, sobre todo, Jerónimo Sempere concedía en este poema una amplitud inédita a la representación de las guerras modernas, marcadas por el desarrollo de las armas de fuego, en los antípodas de la representación del rey soldado y caballero, a la manera de Ticiano. Miguel Martínez ha mostrado cómo Sempere pretende representar de forma realista las "humanas / discordias entre la Christiana gente" (1560: I, 7, vv. 3-4), en las que había participado y de las que habían sido testigo, insistiendo en el protagonismo muy nuevo y decisivo de la infantería -los soldados de a pie- en el marco de las nuevas "guerras de la pólvora" (2010: 98).

Este modelo de narración histórica, inédito a finales de la década de 1550, se plasmó también bajo la pluma del escritor coetáneo Baltasar del Hierro, soldado de las guerras mediterráneas que dedicó por los mismos años dos poemas a la actualidad militar: una relación de la Destruición de África (1560) y una epopeya a los Victoriosos hechos del muy valeroso caballero Don Álvaro de Bazán (1561). Con estos dos poemas, la épica se apoderaba de otra escala narrativa y militar, poniendo el foco en los espacios periféricos de la guerra europea (en vez de un pensamiento global de la geopolítica hispánica) y desarrollando la representación del propio poeta soldado en cuanto 
protagonista del relato heroico (Martínez, 2016). En estos últimos textos, se estrecha la ligazón entre las condiciones de escritura de una epopeya relacionada con los espacios de guerra y la novedad de la inventio, que explora acontecimientos mal conocidos por el público peninsular desde una perspectiva que la crítica llamó, muchas veces de forma inapropiada, "verista".

Este esquema es exactamente el mismo que el que sostiene la empresa ligeramente más tardía de Alonso de Ercilla. A través de las tres partes de La Araucana (1569, 1578, 1589), cuya redacción se remontaría a los años en que sirvió a Felipe II en las guerras de Perú y Chile, el poeta llevó hasta sus más extremas consecuencias el modelo narrativo propuesto por Hierro, uniendo, por un lado, el punto más alejado del imperio, el sur de Chile, con la metrópoli, y construyendo, por el otro, su posición de testigo, de poeta y de héroe de las guerras lejanas (Plagnard, en prensa).

A esta categoría, de la que Ercilla se erige en el máximo representante, se pueden añadir los seis cantos del Sitio y toma de Anvers, publicados en un delgado volumen in octavo (1587) por Miguel Giner, un soldado que participó en la campaña que Alejandro Farnesio emprendió contra la ciudad en 1585 y dedicó al hijo de su protagonista. Uno de los rasgos característicos de este modelo narrativo basado en el ethos del soldado plático se manifiesta a través de los datos numéricos, factuales y onomásticos que proporcionaba el poeta, de acuerdo con la crónica de Alonso Vázquez que fue su principal fuente (Pintacuda, 2014).

Si bien estos textos constituyen un corpus coherente y una vía claramente identificable en el desarrollo del género, oponerlos frontalmente a la tradición italiana sería un contrasentido. Muchos elementos del legado ariostesco permanecen en estos textos: el uso (casi sistemático en este corpus) de la octava real, de los prólogos de los cantos, también muy frecuente, o de los apóstrofes del poeta al dedicatario ya habían pasado a formar parte de un repertorio común. En cambio, el formato editorial movilizado, la materia histórica elegida y el ethos reivindicado por los poetas les distinguían de la narración caballeresca. La idea de una oposición tajante entre épica 
caballeresca y épica de la pólvora, muy operativa en el corpus manejado por Miguel Martínez, merece matizarse en otros casos, como los del mismo Ercilla y del ya mencionado Jiménez de Aillón. El primero no carecía de una cultura aristocrática, habiendo sido, como Luis Zapata y en épocas cercanas, paje de Felipe II, en los mismos años en que Urrea dedicaba al príncipe su Orlando furioso; y, por otro lado, el legado ariostesco en La Araucana es evidente y estructurante en el proyecto de Ercilla, a pesar de su rechazo inicial. A la inversa, el noble Jiménez de Aillón, quien aplicó el modelo ariostesco a la figura medieval del Cid, combatió tanto en Italia como en Flandes y reivindicaba, como Ercilla, haber redactado su poema en los momentos de ocio que le dejaba su vida de soldado, desde el campo de batalla. Sin duda el genio de Ercilla, comparativamente con Aillón, consistió en apostar por la representación de la milicia y elevar su obra a la altura de un espejo de guerreros (Martínez, 2010: 70).

Estos poemas abrieron la vía a una nueva práctica de la épica: la narración en verso (casi siempre en octavas reales) de las batallas más notables de la actualidad, muchas veces basada en crónicas y relatos historiográficos, que floreció durante las décadas de 1570 y 1580 -un modelo cercano al de las guerre in ottava rima en Italia, aunque provisto de elaboración poética notable-. La década de 1570 pareció monopolizada por los relatos sobre la batalla de Lepanto -el de Juan Latino en latín (1572), el de Joan Pujol en catalán (2019 [1573]) y el del portugués Jerónimo Corte-Real en castellano, 1578-, hasta el poema que tanto llamó la atención de Cervantes (Escobar Borrego, 2018), la Austríada de Juan Rufo (2011 [1584]), en el que se promocionaba de forma destacada los nuevos valores de la milicia contemporánea (Oria de Rueda Molins, 2018). La estrecha relación entre esta práctica de la epopeya y los textos históricos en prosa es un fenómeno de gran envergadura que no ha recibido, hasta la fecha, la atención que merece, más allá de algunos estudios aislados. Convoca, no obstante, mecanismos de escritura muy variados, que van de la extracción de informaciones factuales a una imitación textual en la que los poetas ponen en versos fragmentos enteros 
de crónicas. El Victorioso Carlos Quinto de Jerónimo de Urrea con la crónica de Luis de Ávila (Geneste, 1978: 277-288) o la Felicísima victoria de Lepanto de Jerónimo Corte-Real con la Historia de Fernando de Herrera (Plagnard, 2019a: 88-90) son buenas ilustraciones de este fenómeno. Para otros poemas, como el de Ercilla, no se trata de una imitación textual de crónicas, sino de dotar al texto de algunos de los rasgos genéricos característicos de la misma, para dar mayor credibilidad retórica a la verdad alegada del relato (AlbarracínSarmiento, 1966 y Plagnard, 2019a: 88-92).

En paralelo con estas epopeyas de inspiración histórica y militar, se desarrollaron narraciones más breves donde la tonalidad y la retórica épica se combinan con el panegírico, al dedicarse al elogio de un héroe militar claramente identificado. Es el caso de la Breve relación en octava rima de la jornada que ha hecho el Duque de Alba desde España hasta Flandes de Baltasar Vargas (Amberes, Amato Tavernerio, 1568), dedicada al mismo duque, en 192 octavas, y de la Vida del llustrísimo señor Octavio Gonzaga, capitán general de la caballería ligera del estado de Milán del italiano Francesco Balbi da Correggio (1581), que no pasa de 148 octavas. Este último poema fue dedicado simultáneamente, en dos tiradas distintas, a Fernando Gonzaga y Cecilia Médicis Gonzaga, respectivamente sobrino y esposa del difunto héroe, para solicitar protección y merced de parte de la familia de su bienhechor (Baldissera, 2012). llustra claramente cómo el panegírico revistió las formas y los moldes de la épica histórica por las glosas que acompañan cada una de las octavas y se inspiran -incluso textualmente- en una crónica de Pedro Cornejo sobre la guerra de Flandes (Baldissera, 2014, n. 13). Sin embargo, las alusiones mitológicas a lo largo del poema, así como la proposición, inspirada probablemente en el poco conocido poema italiano de Giovanni Alberto Albicante (1538) sobre las guerras del Piamonte, deja patente otra hibridación entre retórica del elogio y el imaginario épico antiguo:

No las troyanas armas coloradas en sangre griega por Héctor famoso, ni las del fiero Aquil ensangrentadas en la troyana, a quien fue tan dañoso; 


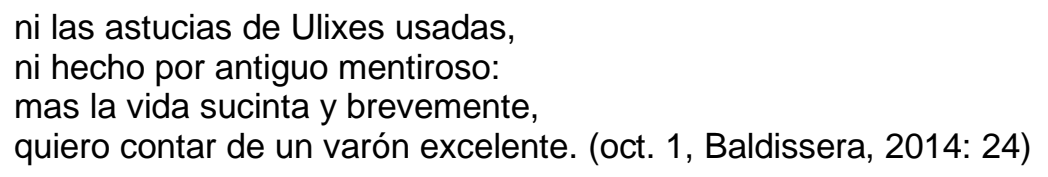

Esta influencia de la épica antigua es el segundo fenómeno visible en las epopeyas históricas que hemos descrito. Mientras que Miguel Martínez (2016: 70), junto con Michael Murrin (1994), sostienen que la épica antigua, donde se representan combates a pie, se prestaba mejor a la representación de la guerra moderna que la épica caballeresca, la imitación de los clásicos responde también a un proyecto político -enlazar las glorias de las naciones modernas a imitación de las del imperio romano (Vilà, 2001)- y estético, para elevar la historia moderna a una dignidad radicalmente nueva. Es este un nuevo factor de diversidad del género épico histórico que nos obliga a matizar la dicotomía sugerida por la parodia del Quijote.

\section{Épica culta}

La imitación por los poetas del legado antiguo de forma directa, y ya no solo a través de la intermediación de Ariosto, debió mucho a las traducciones vernáculas de los grandes poetas de la Antigüedad, que tienen su origen, de nuevo, en la década de 1550. De la misma manera que las traducciones iniciaron lo que llamamos el ciclo orlandino, las traducciones de poemas antiguos constituyeron la primera etapa de una aclimatación renovada de estos textos -en algunos casos, conocidos bajo la forma de las reescrituras tardoantiguas y medievales, como la llias latina- a la lengua vernácula. En este ámbito, la noción de competición entre naciones, que observamos en la épica caballeresca, cede el paso a una relación de dignificación de lo moderno mediante el disfraz de lo antiguo. Para ello, desempeñó un papel imprescindible el traductor de Homero, Gonzalo Pérez.

En 1550, desde la misma ciudad de Amberes en que vio la luz el Orlando furioso de Urrea, se publicó a "Homero hecho ya español", bajo la forma de una Ulixea "en traje castellano" (Pérez, 1550: A4r). La publicación emanaba de nuevo de los círculos cortesanos que rodeaban al príncipe, aquí 
en concreto de su secretario personal, quien también estuvo encargado de constituir su biblioteca (González Palencia, 1946). La historia editorial del poema, publicado en dos tiempos -los trece primeros libros en 1550 y los veinticuatro completos en 1556, en ambos casos después de un intenso proceso de corrección lingüística y estilística, hasta reeditarse con nuevas correcciones en 1562 en Venecia- ilustra a la perfección el cuidado que se puso en este texto, uno de los más importantes testimonios de la penetración de la literatura griega en España, ilustración del humanismo cortesano protagonizado entre España e Italia por letrados y eruditos al servicio de la monarquía hispánica (Guichard, 2006 y 2008; Muñoz Sánchez, 2015: 79-119).

Otros aspectos del texto merecen también nuestra atención: por un lado, la extrema literalidad de la traducción respecto al texto griego original que llegó intacto a la lengua castellana -lejos de los métodos que hemos visto empleados por Urrea o Garrido de Villena traductor-; y, por otro lado, la firme convicción del traductor de que este texto albergaba una lección moral y política útilmente traducible a la modernidad. Así hizo Gonzalo Pérez de su texto un espejo de príncipe destinado a su dedicatario, el joven príncipe Felipe. Lo que para innumerables poetas fue un lugar común -que el rey o el príncipe, por su afición a la guerra tanto como a las letras era el lector ideal de la narración guerrera y, por ende, el dedicatario natural de la épica- se vuelve, bajo la pluma de Gonzalo Pérez, un verdadero "tratado de educación principesca" (Muñoz Sánchez, 2017). La imagen de Felipe como príncipe prudente -fórmula reasumida en un contexto muy distinto bajo la pluma de Juan Caramuel Lobkowitch (1689)- se construye mediante la analogía entre el príncipe en vísperas de su reinado y la lectura humanista de Ulises como príncipe prudente y alegoría del hombre capaz de enfrentarse con los obstáculos y las vueltas de la Fortuna. Las dos versiones de la dedicatoria de Pérez al príncipe son explícitas a este propósito y toman en cuenta el cambio de estatuto del dedicatario entre la versión de 1550, en la que el personaje de Ulises se antoja como un modelo formador, y la de 1556, en que, recién coronado, Felipe ya ostenta las virtudes regias ilustradas en el poema. Las 
prevenciones hacia la literatura griega, en tiempos del concilio de Trento, junto con la menor popularidad del endecasílabo suelto en castellano quizás explican que la traducción de Pérez no gozase de mayor difusión en la segunda mitad del siglo XVI. Sin embargo, varios indicios muestran que esta lectura humanista de la épica antigua encontró eco en la producción castellana de la época.

En efecto, otro traductor recogió un poco más adelante el guante de Gonzalo Pérez en este aspecto, para un texto que tal vez se adecuaba mejor a las ambiciones políticas del joven monarca: la virgiliana narración de los infortunios y éxitos del pius AEneas. Así llegó a afirmar Gregorio Hernández de Velasco que "con justo título, la traducción castellana de la Eneida de Virgilio, el mejor de los Poetas Latinos, se dedica a V.M. el mejor de los reyes cristianos": las dos partes del poema ilustrarían respectivamente la "vida política" y el "arte militar" propias del soberano, bajo el amparo de la figura tutelar de Augusto César, dedicatorio del texto original, "único ejemplar de Príncipes" y de su "piadosa providencia" (1574, f. Tiiiir).

Ahora bien, esta lectura didáctica de la épica antigua -que encuentra su marco teórico en la retórica epidíctica llevada al ámbito político, como señaló Hélio Alves (2001) - coincide con otro poema contemporáneo que durante siglos ha pasado desapercibido, al permanecer en manuscrito. Me refiero al monumental Hércules animoso de Juan de Mal Lara, rescatado del olvido y del precario estado material en el que se encuentra por Francisco Javier Escobar Borrego. En un contexto bien distinto a los años en que Gonzalo Pérez escribía para un príncipe ya maduro y a punto de volverse rey de España, el sevillano Juan de Mal Lara dedicó el objeto de sus desvelos al príncipe Carlos alrededor de 1565, cuando este tenía unos veinte años (Mal Lara, 2015 [ca. 1565]: 21), es decir en una época en la que la indocilidad del príncipe perturbaba fuertemente sus relaciones con el rey. Según declara el poeta, fue su intención, al elegir a Hércules como héroe de su ficción, "declarar un ánimo obediente a quien le puede mandar" (Mal Lara, 2015 [ca. 1565]: 311), un modelo de constancia y sacrificio que él no duda en equiparar con el máximo modelo (histórico) de héroe para el joven príncipe: su abuelo Carlos Quinto, que por los 
mismos años protagonizaba los poemas de Sempere, Zapata y Urrea. El lema del emperador, Plus ultra, con su referencia a las columnas de Hércules, sella, en la dedicatoria a don Carlos, la analogía entre el héroe divino y mitológico y el histórico y verdadero (Mal Lara, 2015 [ca. 1565]: 309). Sin embargo, Juan de Mal Lara, como Gonzalo Pérez, no se contentó con un tópico superficial, sino que explicitó, en una pieza paratextual propia, la "Aplicación de los doce trabajos de Hércules a doce hazañas de César Máximo, Carlos Quinto" (Mal Lara, 2015 [ca. 1565]: 316-319) en la que traza las vidas paralelas de ambos héroes en una verdadera "alegoría política" (Plagnard, 2015).

Volviendo a la traducción de Homero, la importancia de la Ulixea de Gonzalo Pérez radica también en el metro empleado para traducir los hexámetros griegos: el endecasílabo suelto, metro italiano importado a la península por Garcilaso y Boscán en sus respectivas epístola y fábula, y que se adecuaba mejor al funcionamiento acentual y no rimado de la poesía antigua (Muñoz Sánchez, 2015: 87). Si bien esta opción resultó marginal en la épica vernácula posterior (Plagnard, 2019b), es evidente que los pocos ingenios que la practicaron lo hicieron en referencia al legado clásico, y sacaron de esta opción poética muchísimo partido. A la cabeza de ellos, están Gregorio Hernández de Velasco, en su ya mencionada traducción de la Eneida, y Jerónimo Corte-Real, en su poesía tanto portuguesa como castellana ${ }^{12}$.

La primera traducción del poema de Virgilio se publicó en Toledo en 1555 bajo el título de Los doce libros de la Eneida, en un bello in quarto que escondía sin embargo cuidadosamente el nombre del traductor y la identidad de los autores de elogios paratextuales. A pesar de no recibir ninguna ventaja publicitaria por parte de su creador -un eclesiástico de destacada erudición y hábil pluma, que fue capaz de traducir, en el mismo período, tanto El parto de la Virgen de Sannazaro (1554) como Las lágrimas de San Pedro de Tansillo (ca. 1560), según estudió Massimo Caruso, (2016: $42-48$ y 49-56)-, esta

12 Lo emplearían también, fuera del género épico, Diego Hurtado de Mendoza, fray Luis de León, Juan de Mal Lara, Francisco de la Torre o el Lope de Vega del Arte nuevo de hacer comedias en este tiempo. 
traducción enseguida llamó la atención de sus contemporáneos. El flamenco Juan Stelsio, el impresor de la Ulixea, aprovechando quizás la ausencia de privilegio en la edición original, la reimprimió cuatro veces en Amberes en 1557, 1566, 1567 y 1572, en volúmenes de bolsillo de formato in duodequimo y encabezándola con un prólogo en el que insistía en la necesidad de leer a Virgilio, que muchas naciones de Europa, entre ellas Italia y Francia, ya habían traducido a su lengua. Por otra parte, en 1563, se desveló el nombre del traductor con ocasión de la reedición de Pedro de Robles y Antonio de Cormellas en Alcalá de Henares. Hubo que esperar, sin embargo, unos años más para que Gregorio Hernández de Velasco publicara de nuevo, esta vez bajo su nombre, una versión revisada del texto (1574), por las mismas prensas toledanas a las que había recurrido en 1555. Esta nueva edición, con privilegio real y aumentada de una traducción de las Églogas primera y cuarta (f. 7r-8v), del "suplemento" (libro XIII) de Maffeo Veggio (Cristóbal López, 1993) y de una tabla de nombres propios y lugares dificultosos, no gozó de menos fama y éxito que la primera, pues se reimprimió en 1575 en Amberes y animó al autor a publicar una tercera versión revisada en 1577 en Toledo, a su vez reeditada en varias ocasiones hasta 1614. En palabras de Massimo Caruso (2016), quien llevó a cabo la imprescindible tarea de sistematizar el análisis de este proceso editorial, la Eneida de Velasco fue un verdadero bestseller, en cuya historia, añado yo, queda patente la fecundidad de dos momentos para la épica clásica: la década de 1550 y la de 1570-80.

Esta traducción, tan difundida en la segunda mitad del siglo XVI, presenta la particularidad de mezclar los dos tipos de versos que ya se habían aplicado a la épica renacentista: los endecasílabos sueltos, más cercanos al hexámetro dactílico latino, se reservan para traducir las palabras del narrador, mientras que Velasco recurrió a la octava real, de tipo ariostesco, para ornamentar de forma más variada los discursos enchâssés de los personajes, así provistos de una tonalidad más lírica (Plagnard, 2019b; Caruso, 2016: 8595). Bajo la pluma de Hernández de Velasco, se reducía por tanto la distancia, anteriormente muy cultivada, entre el culto legado de la antigüedad y una 
práctica de la épica más orientada a la lectura de un amplio lectorado familiarizado sobre todo con la cultura caballeresca. La atención prestada a la polifonía en este modelo central de la épica renacentista fue sin duda uno de los grandes factores de su éxito.

Este tipo de hibridismo entre el legado antiguo y la moda italiana contemporánea no fue ajeno tampoco al Hércules de Mal Lara, de forma todavía más llamativa pues esta composición no estaba en ningún caso limitada por el exigente ejercicio de la traducción. Recordemos en efecto cómo, al mismo tiempo que obró con erudición, compilando todas las fuentes griegas y latinas a su alcance en la universidad de Salamanca, cuando emprendió su proyecto, y estructurando su poema en doce libros, como la Eneida, Mal Lara no dudó sin embargo en adoptar el metro italiano de la octava real para componer su poema en castellano, y en organizarlo en 48 cantos (el múltiple de 12 más cercano a los 46 cantos del Orlando furioso), ni en recurrir a técnicas narrativas propias del romanzo, de la novela de caballería o de la novela griega, como ha explorado de forma detenida Francisco Javier Escobar Borrego en su edición (2015). El sincretismo del poema de Mal Lara es sin duda una de las mejores demostraciones del complejo hibridismo que albergó el género épico castellano, lejos de las categorías rígidas que la sátira cervantina podría hacernos creer y que encontramos en poemas de menor relieve como la Primera y segunda parte del León de España de Vecilla Castellanos (1586) o La primera parte de la Historia de Sayunto, Numancia y Carthago de Lorencio de Zamora (1589).

Ahora bien, la épica histórica echó mano de este legado antiguo y manifestó, en muchas ocasiones, una erudición que debe mucho a las traducciones de Gonzalo Pérez y de Gregorio Hernández de Velasco. Aunque todavía carecemos de una visión panorámica de la recepción de la épica antigua en las letras áureas en lengua castellana ${ }^{13}$, varios estudios demuestran hasta qué punto la recepción de Homero y Virgilio se hizo mediante el filtro de

${ }^{13}$ El trabajo de Vilà (2021), muy panorámico, se acerca al legado de Virgilio más desde el punto de vista del contenido temático y de la intencionalidad política que de la letra poética. 
Gonzalo Pérez y Gregorio Hernández de Velasco: para la imitación de la Odisea en Os Lusíadas de Luis de Camões (Alves, 2005), para la de la Eneida en La Araucana de Alonso de Ercilla (según prueba la edición de Luis Gómez Canseco, 2021) o bajo la pluma de un Jerónimo Corte-Real ${ }^{14}$. El caso de este último poeta es especialmente llamativo: no solo recurrió a la traducción de Hernández de Velasco para la imitación de muchas escenas concretas y reconocibles -entre otras, las descripciones de las furias y la écfrasis de las armas divinas de su héroe (Plagnard, 2019a: 146-147, 153, 170)- sino que el poema de Virgilio se volvió estructurante en su poema castellano, la Victoria de Lepanto, donde sostiene una parte importante de la fábula (Pozuelo Calero, 2014; Plagnard, 2019a: 379-385). El fenómeno es más importante todavía si tenemos en cuenta que Corte-Real eligió el verso blanco para sus composiciones, y practicó, en especial en su último poema en portugués, una polimetría que puede recordar la de Velasco, aunque no se aplica a los discursos enchâssés, sino a las variaciones del modo imitativo, poniendo énfasis en el canto y en la música instrumental (Plagnard, 2019b).

\section{La década de 1550 y el desarrollo de la épica castellana}

A la luz de este breve acercamiento a las primeras décadas de la épica castellana -género que nutrió la práctica literaria de Cervantes y resonó con su experiencia de militar-, llama la atención el carácter fundador de la década de 1550, así como su conexión con las décadas de 1570-1580, culminación del género tal y como lo representó Cervantes en la biblioteca del hidalgo manchego. La fecha de 1549 marcó en efecto un doble hito. Por un lado, señaló un cambio profundo en la recepción del ya famosísimo Orlando furioso de Ariosto, a partir del cual se fomentó una apropiación de este modelo narrativo en verso y una respuesta capaz de promover figuras genuinamente castellanas del heroísmo medieval. El mercado para este tipo de producto literario, paralelo al de la novela de caballería, explica la profusión de poemas

\footnotetext{
${ }^{14}$ Fuera del ámbito de la épica, es de señalar la imitación de la traducción de Velasco por San Juan de la Cruz, según estudió Calahorro (2019).
} 
de estas características, de calidad, ingenio y fortuna muy dispares, lo cual es señal del atractivo que ejercía entre toda clase de hombres mínimamente capaces de manejar la pluma. Por otra parte, en 1550, Gonzalo Pérez reactivó de forma decisiva el mercado de la traducción vernácula de grandes textos clásicos, asignándole, entre otras cosas, el sentido de un espejo de príncipes en vísperas del reinado de Felipe II. Paralelamente a esta lectura política y didáctica del género, se desarrolló la posibilidad de trasponer, en castellano, los atractivos de la poesía antigua, como bien demuestra el éxito rotundo de la traducción de Gregorio Hernández de Velasco. Así, el período de 1549-1555 aparece como una etapa no solo fecunda, sino coherente y fundadora en la historia del género, en las que las traducciones recibieron, en más de una ocasión, el éxito y el aprecio de poemas originales (Plagnard, 2012b).

Tener en cuenta este contexto inicial en la historia del género nos lleva a reconsiderar la posición de la parte del corpus épico que pasó a la posteridad como la más genuina y original en la literatura castellana: la epopeya militar dedicada a los acontecimientos más impactantes de la actualidad. Cervantes se hace eco del posicionamiento genérico de unos poetas que pretenden atenerse a la narración de acontecimientos verdaderos -sin renunciar por ello a los adornos de la poesía-, en contra de la ficción ariostesca. Ahora bien, este corpus se revela, a pesar de esta postura explícita, deudor en proporciones variables de las dos propuestas formuladas en paralelo a partir de 1549. De nuevo, La Araucana aparece como un excelente ejemplo de síntesis entre el humor y las técnicas narrativas de Ariosto, de las que es inequívocamente deudor a pesar del contrapié proclamado de la primera octava (Chevalier, 1966: 144-160, Blanco, 2012), y las creaciones de Virgilio, en quien modela por ejemplo los juegos araucanos del décimo canto, y Lucano, cuya Ericto sirve de punto de partida para el personaje del mago Fitón (Nicolopulos, 2001; y Plagnard, 2019a: 212-217, para más bibliografía). El atractivo de este poema en Cervantes pudo resultar de la postura del soldado, testigo, y héroe de Ercilla. 
Sin embargo, es evidente que fue en cuanto poesía (Blanco, 2013) como este modelo le resultó más convincente, cifrándose esta influencia en la escena de la espada de don Quijote suspendida en alto encima del vizcaíno entre los capítulos 8 y 9 de la primera parte, a imagen y semejanza de la de Tucapel encima de Rengo entre la Segunda parte y la Tercera de la Araucana, y extendiéndose a muchos lugares del poema que permite rastrear en parte la edición de Luis Gómez Canseco (2021 [1569-1589]). Por otra parte, el interés de Cervantes por episodios novelescos también pudo ser filtrado por la épica histórica de corte más virgiliano e histórico, como fue el caso del trio amoroso formado por los capitanes otomanos Mustafa Bajá y Pialí Bajá y la griega Hipólita en la épica lepantina, en los que está modelada la trama de El amante liberal y los personajes de Alí Bajá, Hasán Bajá y de Leonisa (Plagnard, 2012c). Así se explica, sin lugar a dudas, el destacado lugar que le da Cervantes al poema de Luis Barahona de Soto sobre los amores de Angélica y Medoro: por su calidad poética y por la elección de un hilo narrativo donde la cuestión de la verdad y de la historia se quedaba oportunamente al margen. La relación entre la épica y la producción cervantina es, sin lugar a dudas, un campo que nos reserva todavía muchas sorpresas.

\section{Bibliografía}

\section{Corpus épico citado en sus ediciones originales}

ÁVILA Y ZÚNIIGA, Luis de (1549). Comentario del ilustre señor don Luis de Ávila y Zúñiga de la guerra de Alemania, hecha de Carlo V. Máximo Emperador Romano, Rey de España. En el año de M.D.XLVI. y M.D.XLVII. Amberes: Juan Steelsio (varias reediciones hasta 1552).

ARIOSTO, Ludovico (1549). Orlando Furioso, trad. Jerónimo de Urrea. Amberes: Martín Nucio (reeds. Lyon: Guillaume Rouillé 1550 y 1556; Venecia: Giolito de Ferrari, 1553; Amberes: viuda de Martin Nuits, 1558...).

ARIosto, Ludovico (1550). Orlando furioso, trad. Hernando Alcocer. Toledo: Juan Ferrer.

Homero (1550). La Ulixea de Homero. XIII libros, trad. Gonzalo Pérez. Salamanca: Andrea de Portonariis (ed. simultánea revisada en Anvers, Juan Steelsio, 1550; reed. Venecia, Gabriel Giolito de Ferrariis, 1553).

BoIARDO, Matteo Maria (1555). Los tres libros de Mattheo Maria Boyardo conde de Scandiano, llamados Orlando Enamorado, trad. Francisco Garrido de Villena. Valencia: Joan Mey (reeds. Alcalá de Henares, Hernán Ramírez, 
1577 y Toledo, Juan Rodríguez, 1581).

GARRIDO DE VILLENA, Francisco (1555). El Verdadero suceso de la famosa batalla de Roncesvalles; con la muerte de los doce pares de Francia. Valencia: Joan Mey (reed. Toledo, Juan Rodríguez, 1583).

ESPINOSA, Nicolás (1555). La segunda parte de Orlando: con el verdadero suceso de la famosa batalla de Roncesvalles, fin y muerte de los doce pares de Francia. Zaragoza: Pedro Bermuz. (reeds. Amberes, Martín Nuncio, 1556).

VIRGILIO (1555). Los doce libros de la Eneida de Virgilio traducida en octava rima y verso Castellano, trad. Gregorio Hernández de Velasco. Toledo: Juan de Ayala.

Homero (1556). La Ulixea de Homero [24 libros], trad. Gonzalo Pérez. Amberes: Juan Steelsio (reed. Venecia, Francisco Rampazeto, 1562).

SemPERE, Jerónimo (1560). Primera [Segunda] parte de la Carolea: trata las victorias del Emperador Carlos V Rey de España. Valencia: Joan de Arcos.

HierRo, Baltasar del (1560). Destruición de África, ahora nuevamente por muy gentil estilo compuesta. Sevilla: Sebastián Trugillo.

HierRo, Baltasar del (1561). Libro y primera parte de los victoriosos hechos del muy valeroso caballero Don Álvaro de Bazán. Granada: René Rabut.

ZAPATA, Luis (1566). Carlo famoso. Valencia, Joan Mey.

VARGAS, Baltasar de (1568). Breve Relación en octava Rima de la jornada que a hecho el Illmo. y exmo. Señor Duque d'Alva desde España hasta los estados de Flandes. Amberes: Amato Tavernerio.

JiMENÉZ dE AilLón, Diego (1568). Los Famosos y heroicos hechos del invencible y esforzado caballero, honra y flor de las Españas, el Cid Rui Díaz de Vivar: con los de otros varones ilustres d'ellas, no menos dignos, de fama y memorable recordación, en octava rima. Amberes, viuda de Juan Lacio (reed. Alcalá de Henares: Juan Íñiguez de Lequerica, 1579).

Ercilla, Alonso de (1569). La Araucana. Madrid: Pierres Cossin (múltiples reeds).

VIRGILIO (1574), Los doce libros de la Eneida de Virgilio, príncipe de los poemas Latinos, traducida en octava rima y verso Castellano; ahora en esta última impresión reformada y limada con mucho estudio y cuidado, de tal manera que se puede decir nueva traducción, trad. Gregorio Hernández de Velasco. Toledo: Juan de Ayala (reimpr. Amberes: s.n., 1575; y reed. Toledo: Diego de Ayala, 1577, con varias reimpr. hasta 1614).

ERcIlLA, Alonso de (1578). Primera y segunda parte de la Araucana. Madrid: Pierres Cossin (múltiples reeds).

BOLEA y CASTRO, Martín de (1578b). Libro de Orlando determinado que prosigue la materia de Orlando el Enamorado. Lérida: Miguel Prats.

BALBI DE CorRegGio, Francisco (1581). Vida del Ilustrísimo Señor Octavio Gonzaga Capitán general de la caballería ligera del estado de Milán. Barcelona: Hubert Gotard.

SANS, Hipólito (1582). La Maltea: en que se trata la famosa defensa de la 
Religión de Sant Joan en la isla de Malta. Valencia: Joan Navarro.

GÓMEZ DE LUQUE, Gonzalo (1583). Libro primero de los famosos hechos del principe Celidon de Iberia compuesto en estancias. Alcalá de Henares: Juan Î̃iguez de Lequerica .

RuFo GutiÉRREZ, Juan (1584). La Austriada. Madrid: viuda de Alonso Gómez (reeds. Toledo: Juan Rodríguez, 1585; Alcalá de Henares: Juan Gracián, 1586).

Alonso, Agustín (1585). Historia de las hazañas y hechos del invencible cavallero Bernardo del Carpio. Toledo: Juan Boyer, mercader de libros, por Pero López de Haro.

García dE AlARCón, Gaspar (1585). La victoriosa conquista que don Álvaro Bazán Marqués de sancta Cruz hizo en las Islas de los Azores, el año de 1583. Valencia: Joan Navarro por Vincente de Miravet.

Barahona de Soto, Luis (1586). Primera parte de la Angélica. Granada: Hugo de Mena.

Vecilla Castellanos, Pedro de la (1586). Primera y segunda parte de El León de España. Salamanca: Juan Fernández.

Giner, Miguel (1587). El sitio y toma de Anvers. Milán: Pacífico Poncio.

VIRUÉS, Cristóbal de (1587). El Monserrate. Madrid: Querino Gerardo.

HUERTA, Jerónimo de (1588). Florando de Castilla: lauro de caballeros compuesto en octava rima. Alcalá de Henares: Juan Gracián.

ERCILLA, Alonso de (1589). Tercera parte de la Araucana. Madrid: Pedro Madrigal (múltiples reeds).

DIAS, Duarte (1590). La Conquista que hicieron los poderosos y Católicos Reyes Don Fernando y Doña Isabel, en el reino de Granada. Madrid: Alonso Gómez.

\section{Bibliografía crítica}

Alves, Hélio J.S (2001). Camões, Corte-Real e o sistema da epopeia quinhentista. Coimbra: Centro Interuniversitário de Estudos Camonianos.

Alves, Hélio J. S. (2005). "Presença da Odisseia em Camões", Revista Camoniana, 17, pp. 39-46.

AlbiCANTE, Giovanni Alberto (1538). Historia della guerra del Piamonte. Milán: Gianantonio da Castiglione.

ARIOsto, Ludovico (2002). Orlando furioso, María de las Nieves Muñiz (ed.). Madrid: Cátedra.

BALDISSERA, Andrea (2012). "Francesco Balbi da Correggio y La vida del ilustríssimo señor don Octavio Gonzaga", Paratesto, 9, pp. 45-56.

BALDISSERA, Andrea (2014). "La vida del ilustríssimo señor Octavio Gonzaga de Francesco Balbi da Correggio. Estudio y edición”. En Paolo Pintacuda (dir.), Le vie dell'épica ispanica. Lecce-Brescia: Pensa Multimedia, pp. 11-93.

BARAHONA DE SOTO, Luis (1981). Las lágrimas de Angélica [1586], José Lara Garrido (ed.). Madrid: Cátedra.

BLANCO, Mercedes (2012). "Sur les frontières mouvantes de l'historiographie et 
de l'épopée : l'Araucana d'Alonso de Ercilla (1569-1589)". En Sangirardi, Giuseppe, Paloma Bravo y Cécile Iglesias (dir.), La Renaissance des genres. Pratiques et théories des genres littéraires entre Italie et Espagne (XVe-XVIle siècles). Dijon: Presses de l'Université de Dijon, pp. 241-265.

BLANCO, Mercedes (2013). "La épica áurea como poesía”. En Rodrigo Cacho Casal y Anne Holloway (eds.), Los géneros poéticos del Siglo de Oro: centros y periferias. Woodbridge, Suffolk: Tamesis, pp. 14-30.

CACHO CASAL, Rodrigo (2012). "Luis Zapata y el poema heroico: historia, entretenimiento y parodia", Criticón, 115, número monográfico "La poesía épica en el Siglo de Oro" (dir. Rodrigo Cacho Casal), pp. 67-83.

CALAHORRO, Inmaculada López (2019). "La Eneida de Gregorio Hernández de Velasco: relación con Cántico espiritual y Llama de amor viva de San Juan de la Cruz", Florentia lliberritana, 30, pp. 147-164.

CaRAmuel LoBkowitch, Juan (1689). Philippus prudens Caroli V. imp. filius Lusitaniae, Algarbiae, Indiae, Brasiliae legitimus rex demostratus. Amberes: Baltasar Moretus (oficina de Plantino).

Cervantes, Miguel de (2015). Don Quijote de la Mancha [1605], Francisco Rico (ed.). Madrid: Real Academia Española.

CheVAliER, Maxime (1966). L'Arioste en Espagne : 1530-1650. Recherches sur I'influence du "Roland furieux". Bordeaux: Féret et fils.

CRIstóbal LÓPEZ, Vicente (1993). "Maffeo Regio y su libro XIII de la Eneida", Cuadernos de Filología Clásica. Estudios latinos, 5, pp. 189-210.

DAVIS, Elizabeth B. (2000). Myth and Identity in the Epic of Imperial Spain. Columbia: University of Missouri Press.

ERCILla y ZUÑIGA, Alonso de (2021). La Araucana [1569-1589], Luis Gómez Canseco (ed.). Madrid: Real Academia Española.

Escobar BorREgo, Francisco J. (ed.). Juan de MAL LARA (2015). Introducción a Hércules animoso [ca. 1565]. Ciudad de México: Frente de Afirmación Hispanista.

Escobar BorREgo, Francisco J. (2018). "Materiam superabat opus: Cervantes, cautivo lector de Rufo (al trasluz de la modalidad épico-novelesca en La Austríada y los Apotegmas)", Creneida, 6 ("La musa circunflexa de Juan Rufo"), pp. 146-198.

GENESTE, Pierre (1978). Le capitaine aragonais Jerónimo de Urrea, sa vie, son œuvre ou chevalerie et Renaissance dans l'Espagne du XVlème siècle. Paris: Ediciones hispanoamericanas.

González Palencia, Ángel (1946). Gonzalo Pérez secretario de Felipe II. Madrid: Instituto Jerónimo Zurita.

GuICHARD, Luis Arturo (2008). "Un autógrafo de la traducción de Homero de Gonzalo Pérez (Ulyxea XIV-XXIV) anotado por Juan Páez de Castro y el Cardenal Mendoza y Bovadilla", International journal of the classical tradition, 2008, 15-4, pp. 525-557.

GuichARD, Luis Arturo (2006). "La Ulixea de Gonzalo Pérez y las traducciones latinas de Homero'". En Barry Taylor y Alex Coroleu (dir.), Latin and Vernacular in Renaissance Iberia II: Translations and Adaptations. 
Manchester: Manchester University Press, pp. 49-72.

JAVITCH, Daniel (1991). Proclaiming a classic: the canonization of Orlando furioso. Princeton: Princeton university press.

Kammerer, Elsa, Plagnard, Aude et RajChEnbach-Teller, Élise (2015). "Entre stratégies commerciales et «illustration» des vulgaires romans: la boutique de Guillaume Roville à Lyon (1548-1556)". En Elsa Kammerer et Jan-Dirk Müller (dir.) Les ateliers d'imprimeurs, lieux d'expérimentation des langues vernaculaires en Europe (fin XVe - XVle siècles) [projet Eurolab, volume 1]. Genève: Droz, pp. 443-487.

KING, Willard F. (1979). "Cervantes' Numancia and Imperial Spain”, MLN, 94-2, pp. 200-221.

LARA GARRIDO, José (ed.). Luis BARAHONA DE SOTO (1981). Las lágrimas de Angélica [1586]. Madrid: Cátedra.

LEAVITT, Sturgis E. (1947). "Cervantes and Heroic Verse”, Hispanic Review, XV.

LLEDÓ-GUILLEM, Vicente (2013). "La polifonía épica en El Monserrate: la voz del amor de Lixerea y Armeno", Neophilologus, 2013, 97-1, pp. 65-83.

MAL LARA Juan de (2015). Hércules animoso [ca. 1565], Francisco Javier Escobar Borrego (ed.). Ciudad de México: Frente de Afirmación Hispanista.

MARTíneZ, Miguel (2010). Prácticas y Representaciones Del Imperio. Guerra, Imprenta y Espacio Social en la Épica Hispánica del Quinientos [tesis doctoral inédita]. New York: City University of New York.

MARTínEZ, Miguel (2011). "Género, imprenta y espacio social: una «poética de la pólvora» para la épica quinientista", Hispanic Review, 79-2, pp. 163-187.

MARTÍNEZ, Miguel (2016). Front lines: soldiers' writing in the early modern hispanic world. Philadelphia: University of Pennsylvania Press.

MuÑoz SÁNCHEZ, Juan Ramón (ed.). Gonzalo PÉREZ (2015). Introducción a La Ulixea de Homero, traducida de griego en lengua castellana por el secretario Gonzalo Pérez. Anejo de Analecta Malacitana, 99. Málaga: Universidad de Málaga.

MUÑOZ SÁNCHEZ, Juan Ramón (2017). “«El mejor de los poetas» para «el mejor de los príncipes»: La Ulixea de Homero, traducida de griego en lengua castellana por el secretario Gonzalo Pérez, un tratado cortesano de educación principesca", Calíope, 22-1, pp. 141-163.

MuRRIN, Michael (1994). History and warfare in Renaissance epic, ChicagoLondon: University of Chicago press.

ORIA DE RuEdA Molins, Marta Cristina (2018). "Los valores de la nueva milicia en La Austríada", Creneida, 6, número monográfico "La musa circunfleja de Juan Rufo", pp. 260-291.

Oria DE Rueda Molins, Marta Cristina (2019). "El Monserrate de Cristóbal de Virués: la presencia de lo maravilloso en la épica hispánica". En Carlos Mata Induráin y Sara Santa Aguilar (dir.), Ars longa. Acta del VIII congreso internacional 'Jóvenes Investigadores Siglo de Oro' (JISO 2018). Pamplona: Biadig (Biblioteca áurea digital del GRISO), pp. 279-297. 
PÉreZ, Gonzalo (2015). La Ulixea de Homero, traducida de griego en lengua castellana por el secretario Gonzalo Pérez, Juan Ramón Muñoz Sánchez (ed.). Anejo de Analecta Malacitana, 99. Málaga: Universidad de Málaga.

PIERCE, Frank (1961). La poesía épica del siglo de oro. Madrid: Gredos.

PINTACUDA, Paolo (2014). "Sobre las dos versiones del Sitio y toma de Amberes de Miguel Giner". En Paolo Pintacuda (dir.), Le vie dell'épica ispanica. Lecce-Brescia: Pensa Multimedia, pp. 95-122.

PlagnaRD, Aude (2012a). "Valence héroïque : premiers poèmes épiques espagnols de la fin du règne de Charles-Quint (Nicolás Espinosa et Francisco Garrido de Villena, 1555)", e-Spania, 13, número monográfico "Les Poètes de l'Empereur. La cour de Charles-Quint dans le renouveau du XVle siècle (1516-1556)" (dir. Roland Béhar y Mercedes Blanco).

PlagnaRd, Aude (2012b). "Homero hecho ya español ou la traduction comme événement. Poèmes antiques et italiens en vers espagnols (15491556)", Mélanges de la Casa de Velázquez, 42-1, número monográfico "Tres momentos de cambio en la creación literaria del Siglo de Oro" (dir. Mercedes Blanco), pp. 17-34.

PlagnaRd, Aude (2012c). "Cautivas cristianas y enamorados turcos", Criticón, 115, número monográfico "La poesía épica en el Siglo de Oro" (dir. Rodrigo Cacho Casal), 2012, pp. 125-145.

Plagnard, Aude (2015). Reseña de Juan de Mal Lara, Hércules animoso, ed. Francisco Javier Escobar Borrego. México: Frente de Afirmación Hispanista, 1835 p., Crítica hispanica, 37-2, pp. 252-260.

Plagnard, Aude (2019b). "Polimetría en la épica quinientista", Bulletin hispanique, 121-1, número monográfico "La épica en el mundo hispánico (Siglo de oro)" (dir. Lise Segas), pp. 119-160.

PlagnaRd, Aude (en prensa). "Eyewitness, hero, and poet: Ercilla in the three parts of La Araucana". En Emiro Martínez Osorio y Mercedes Blanco (dir.), The War Trumpet. The Age of Iberian Epic. Toronto: Toronto University Press (en curso de evaluación).

PONCE CÁRDENAS, Jesús (dir.) [2018]. Lope de Vega y el humanismo cristiano. Madrid-Frankfurt am Main: Iberoamericana-Vervuert.

Pozuelo CALERo, Bartolomé (2014). "Transmutando la historia contemporánea en epopeya virgiliana: La Felicísima victoria de Jerónimo de Corte Real". En Paula Morão y Cristina Pimentel (dir.), Matrizes Clássicas da Literatura Portuguesa: uma (re)visão da literatura portuguesa das origens à contemporaneidade. Lisboa: Campo da Comunicação, pp. 169-178.

PuJoL, Joan (2019). Els poemes de Lepant, Eulàlia Miralles y Pep Valsalobre (ed.). Barcelona: Editorial Barcino.

RuFo, Juan (2011). La Austríada [1584], Ester Cicchetti (ed.). Como: Ibis.

RupP, Stephen (2014). Heroic Forms: Cervantes and the Literature of War. Toronto: University of Toronto Press.

VAlsalobre, Pep (2005). "Una cort italianitzant a València: notes sobre la recepció d'Ariosto a Espanya", Quaderns d'Italià, 2005, 10, pp. 219-241. 
VAlsalobre, Pep (2003). "Una cort «ferraresa» a València: els Centelles, Ariosto i un programa de substitució de la tradició literària autóctona", Caplletra: revista internacional de filología, 34, pp. 171-194.

VILÀ, Lara (2001). Épica e imperio. Imitación virgiliana y propaganda política en la épica española del siglo XVI [tesis doctoral inédita]. Barcelona: Universitat Autònoma de Barcelona.

VILÀ, Lara (2011). "Libros grandes, libros pequeños: una nota sobre las lecturas épicas de Alonso Quijano", Studia Aurea, 5, pp. 129-141.

ZATTI, Sergio (1990). II Furioso fra epos e romanzo. Lucca: Pacini Fazzi.

Fecha de recepción: 9 de mayo de 2021

Fecha de aceptación: 31 de mayo de 2021 